\title{
ANAESTHESIA FOR DILATATION, EVACUATION AND CURETTAGE IN OUTPATIENTS: COMPARISON OF SUBANAESTHETIC DOSES OF KETAMINE AND SODIUM METHOHEXITONE-NITROUS OXIDE ANAESTHESIA
}

\author{
Eduardo M. Figallo, Ray McKenzie, Boonrax Tantisira, Rajindar K. Wadhwa, \\ and Ceferino S. Sinchioco
}

Ketamine is a safe intravenous anaesthetic agent which produces profound somatic analgesia, amnesia and a sleep-like state followed by a high incidence of dreaming and diplopia. We sought to retain analgesia and amnesia and eliminate dreaming and diplopia by the use of sub-anaesthetic doses. To this end we compared ketamine to methohexitone-nitrous oxide-oxygen anaesthesia in a matched series of patients and assessed recovery times.

\section{METHODS}

Sixty-four female patients in Physical Status I, ranging in age from 15 to 34 years, undergoing dilatation, evacuation and curettage ( $D E \& C$ ) were selected for this study. Patients with a history of psychiatric disturbances were excluded.

All patients received atropine $0.4 \mathrm{mg}$ and droperidol $2.5 \mathrm{mg} 15$ minutes before induction of anaesthesia.

Thirty-two patients in the first group were given an intravenous bolus of methohexitone $1 \mathrm{mg} / \mathrm{kg}$ body weight for induction of anaesthesia. Anaesthesia was maintained with a mixture of nitrous oxide-oxygen and an intravenous drip of succinylcholine 0.2 per cent when needed.

The second group of 32 patients received intravenous ketamine administered in fractional doses up to an average total of $0.49 \mathrm{mg} / \mathrm{kg}$. Explanation of the details of this form of administration of ketamine was given to every patient in this group.

After the patient had been placed into lithotomy position, she was told about the surgical preparation of the genital area. Surgeons used lukewarm antiseptic solution for this preparation. Following surgical draping, an initial intravenous dose of ketamine $20 \mathrm{mg}$ was administered. If a brief period of unconsciousness occurred the surgeon was asked to delay the procedure until oral communication between anaesthetist and patient had been re-established. We considered this to be of utmost importance for the success of this technique. After the bimanual pelvic examination, and shortly before dilatation of the cervix, a second dose of $10 \mathrm{mg}$ of ketamine was administered.

In some cases when the surgical procedure lasted longer than expected a third dose of ketamine $20 \mathrm{mg}$ was given intravenously. After completion of the procedure patients were transported to the outpatient recovery room, where they

Department of Anesthesiology, Magee-Womens Hospital, Pittsburgh, Pennsylvania 15213.

Canad. Anaesth. Soc. J., vol. 24, no. 1, January 1977 
FIGALLO, et al.: KETAMINE AND SODIUM METHOHEXITAL-NITROUS OXIDE $\mathrm{O}_{2} \quad 111$ remained under nursing supervision until their discharge by one of the staff anaesthetists.

The recovery-room nurses were instructed to evaluate the recovery with regard to orientation as to name, time and place, clearing of vision, and also by direct questioning of the patient every 15 minutes. Return to normal visual motor coordination was assessed by serial performances of the Trieger Test. ${ }^{1}$ Recovery of visual motor coordination was assumed when the scoring of this test had returned to the preoperative baseline value.

Amnesia studies were performed following Gruber and Reed guidelines ${ }^{2}$ utilizing a coloured block that was shown to the patients shortly before administration of the premedication and again within half an hour after the patients had arrived in the recovery room.

\section{RESULTS}

Table I shows the general characteristics of the two groups of patients. They are quite comparable with the exception of the surgical time, which was longer for the methohexitone-nitrous oxide group, with a mean duration of 10.57 minutes compared to 7.31 minutes for the ketamine group.

Table II shows that the most frequent individual dose of ketamine was $30 \mathrm{mg}$. It was administered to 26 of 32 patients. Age and other factors that might affect the anatomical condition of the cervix did not seem to influence the dose requirements of ketamine.

We were able to obtain a brief but good analgesic effect in 26 of the 32 patients ( 81 per cent) for an average anaesthetic time of seven and a half minutes (Table III). Six patients ( 19 per cent) complained of pain or discomfort during the operative procedure, particularly during dilatation of the cervix, but with continuous reassurance by the anaesthetist they were able to tolerate the rest of the procedure without the need to increase the dose of ketamine beyond the $40 \mathrm{mg}$ total individual dose set as limit for this study.

Vocalization was present in 24 of the 32 patients. In six of these patients ( 19 per cent) vocalization was the expression of pain or discomfort. In 21 patients (65 per

TABLE I

General Characteristics

\begin{tabular}{|c|c|c|c|c|c|}
\hline & $\begin{array}{c}\text { Number of } \\
\text { patients }\end{array}$ & $\begin{array}{l}\text { Age } \\
\text { (Yrs) }\end{array}$ & $\underset{(\mathrm{cm})}{\text { Height }}$ & $\begin{array}{c}\text { Weight } \\
(\mathrm{kg})\end{array}$ & $\begin{array}{l}\text { Operating } \\
\text { time } \\
\text { (minutes) }\end{array}$ \\
\hline $\begin{array}{l}\text { Group I } \\
\text { I.V. methohexitone* } \\
\text { Nitrous oxide }\end{array}$ & 32 & $\begin{array}{r}22.60 \\
\pm 6.45\end{array}$ & $\begin{array}{l}143.1 \\
\pm 5.58\end{array}$ & $\begin{array}{c}58.5 \\
\pm 8.23\end{array}$ & $\begin{array}{r}10.57 \\
\pm 4.21\end{array}$ \\
\hline $\begin{array}{l}\text { Group II } \\
\text { Subanaesthetic } \\
\text { I.V. ketamine }\end{array}$ & 32 & $\begin{array}{r}22.78 \\
\pm 5.53\end{array}$ & $\begin{array}{l}145.7 \\
\pm 2.27\end{array}$ & $\begin{array}{c}59.2 \\
\pm 8.52\end{array}$ & $\begin{array}{r}7.30 \\
\pm 4.14\end{array}$ \\
\hline
\end{tabular}

* Methohexitone $1 \mathrm{mg} / \mathrm{kg}$.

All patients received I.V. atropine, $0.4 \mathrm{mg}(1 \mathrm{ml})$ and $I . V$. droperidol, $2.5 \mathrm{mg}(1 \mathrm{ml})$. 
TABLE II

Total Dose of Ketamine

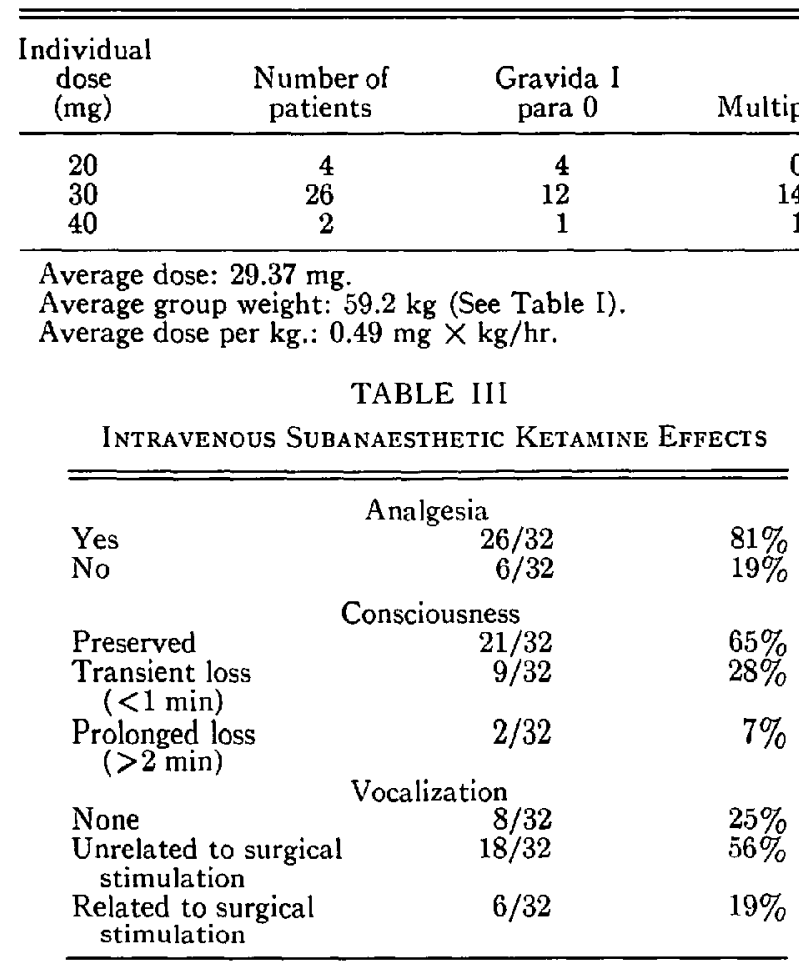

TABLE IV

Intra-operative Course Events

\begin{tabular}{lcc}
\hline & Group I* & Group I I \\
\hline Hiccup & $5 / 32$ & $0 / 32$ \\
Airway obstruction & $3 / 32$ & $0 / 32$ \\
Use of muscle relaxants & $29 / 32$ & $0 / 32$ \\
Vomiting & $2 / 32$ & $0 / 32$ \\
Psychomotor excitation & $0 / 32$ & $2 / 32$ \\
\hline
\end{tabular}

*Group I were given methohexitone-nitrous oxide.

†Group II were given subanaesthetic ketamine, 0.49 $\mathrm{mg} / \mathrm{kg}$.

cent) consciousness became slightly clouded, but they were still able to respond and understand oral commands given by the anaesthetist.

Table III shows that nine patients ( 28 per cent) were unresponsive for a period of not more than one minute. In two patients communication with the anaesthetist was never adequately re-established. Both developed psycho-motor excitation requiring general anaesthesia.

Table IV compares complicating events during the operation in the two groups. In the methohexitone-nitrous oxide group, 5 of 32 patients had hiccup immediately after the administration of the bolus of barbiturate. Three had some obstruction of the upper airway during induction, which require insertion of an oral airway; and in 29 patients an intravenous drip of succinylcholine was needed for smooth 
TABLE V

Immediate Emergence Reactions (0-6 Hours)

\begin{tabular}{lcc}
\hline & Group I & Group II \\
Dreams & $3 / 32$ & $6 / 32$ \\
Unpleasant dreams & $0 / 32$ & $6 / 32$ \\
Visual hallucinations & & \\
and/or illusions & $0 / 32$ & $0 / 32$ \\
Psychomotor excitation & $0 / 32$ & $0 / 32$ \\
\hline
\end{tabular}

TABLE VI

AMNESIA STUDY*

\begin{tabular}{lrc}
\hline \hline & Group I & Group II \\
Anterograde amnesia & $20 / 32$ & $4 / 32$ \\
Retrograde amnesia & $3 / 32$ & $4 / 32$ \\
& & \\
Pain & Intraoperative events & \\
Voices & $0 / 32$ & $0 / 32$ \\
& $0 / 32$ & $2 / 32$ \\
\hline
\end{tabular}

*Gruber, R.P. and Reed, D.R.

Group I - Sodium methohexitone-nitrous oxide. Group II - Subanaesthetic ketamine.

maintenance of anaesthesia. Two patients vomited - one during induction of and the other during emergence from anaesthesia. In both cases the vomitus consisted of clear liquid and the outcome was uneventful. None of these phenomena were observed in the ketamine group but psychomotor excitation occurred twice

Table $\mathrm{V}$ compares the frequency of dreams and post-operative psychomimetic reactions in the two groups of patients. Dream-like activity was present in both groups. With methohexitone-nitrous oxide 3 of 32 patients ( 9 per cent) claimed they had dreams, whereas in the ketamine group six patients ( 18 per cent) recalled dreams. The difference lay in the nature and intensity of the dreams: in the methohexitone-nitrous oxide group dreams were of the usual kind, whereas in the ketamine group they were unpleasant vivid dreams.

Amnesia was studied using the coloured block method ${ }^{2}$ (Table VI). This showed that in the methohexitone group 12 of 32 patients ( 37 per cent) had true postoperative anterograde amnesia (the combined effect of the premedication and anaesthesia), compared to only four patients (12 per cent) in the ketamine group. Despite this finding, 30 of the 32 patients (93 per cent) on ketamine were unable to recall any intra-operative events. Neither the noise of the suction machine nor the anaesthetist talking to them constantly were recalled. Far more important, the pain or discomfort expressed by some during the operation was not remembered.

Figure 1 shows that all patients in both groups had clinical recovery as to name, place, and time orientation within the first 45 minutes after arrival in the recovery room. There was a slight advantage in the methohexitone group, when compared to the ketamine group, in regard to the subjective recovery of clear vision. Both groups, with the exception of one patient in the ketamine group, had recovery of clear vision within 60 minutes of arrival in the recovery room.

Patient co-ordination according to the Trieger Test returned to the preoperative baseline level in 18 of 24 patients ( 81 per cent) in the methohexitone group and in 


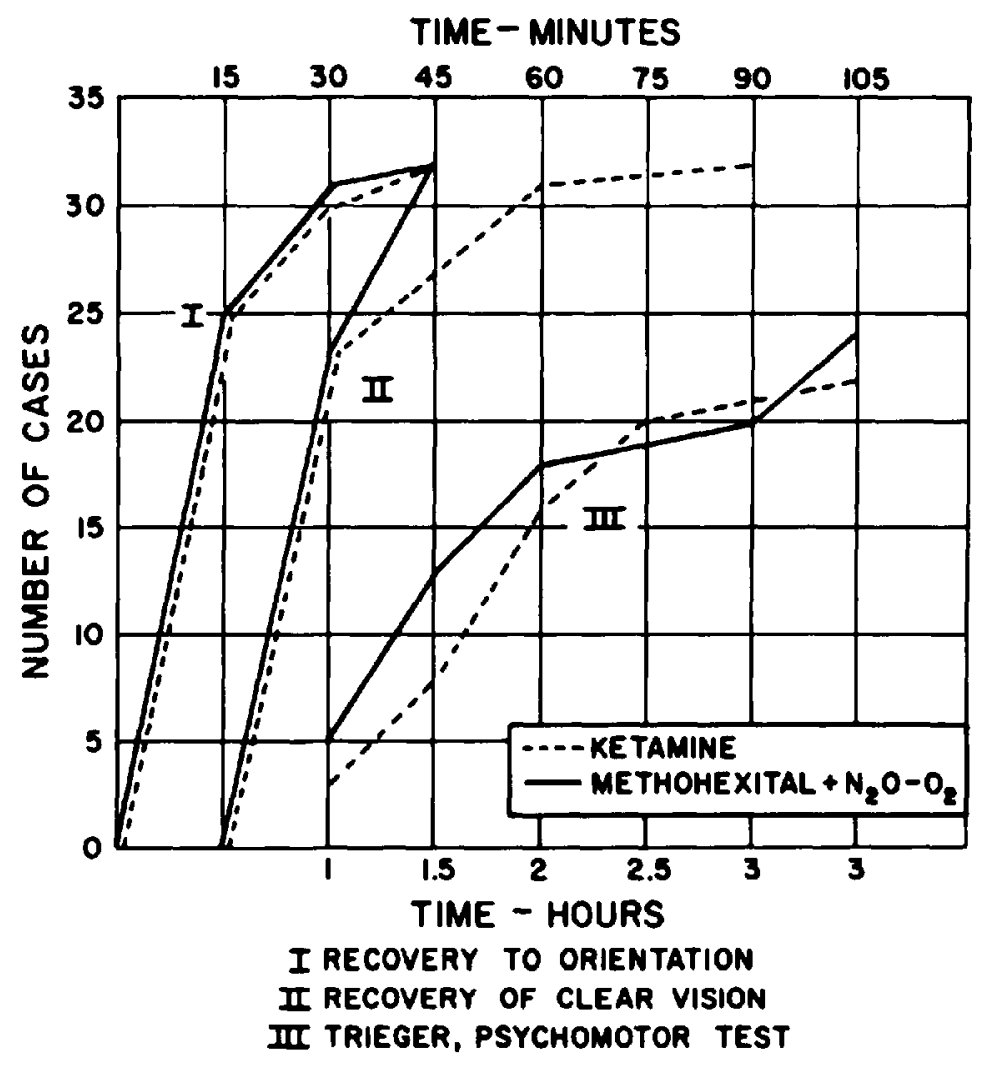

Figure 1

16 of 22 patients ( 71 per cent) in the ketamine group within two hours of their arrival in the recovery room (Figure 1). Four patients in the barbiturate group had a delay of over three hours in return of their ability to carry out this test to the baseline value. These four patients had the longest anaesthesia time.

Rating of the anaesthetic by the anaesthesia personnel was similar for both groups: 24 of 32 patients ( 75 per cent) in the methohexitone group and 22 of the 32 patients ( 68 per cent) in the ketamine group was judged to have been satisfactory. The high incidence of vocalization during operation and the expression of pain or discomfort by some patients were the main reasons for the unfavourable rating of the ketamine group. Hiccup and difficulty in maintaining the airway were the main complaints in the methohexitone-nitrous oxide group.

The surgeons' rating of the operative conditions provided by subanaesthetic doses of ketamine as the sole agent was lower than that for the methohexitone group. In the ketamine group operative conditions were rated as good by the surgeons in 23 of 32 patients ( 71 per cent) compared to 30 of 32 patients ( 93 per cent) in the methohexitone group. Lack of adequate abdominal muscle relaxation for the bimanual pelvic examination before the actual operation, was the most common complaint by the surgeons, with an incidence of 7 of 32 patients ( 21 per cent) in the ketamine group.

The patient's rating of the anaesthesia experience was similar for both groups. 
FIGALLO, et al: : KETAMINE AND SODIUM METHOHEXITAL-NITROUS OXIDE $\mathrm{O}_{2} \quad 115$

Twenty-five of 32 patients ( 78 per cent) in each group rated the experience as satisfactory. Despite the fact that the anaesthesia experience was rated as similar by the patients of both groups, future acceptance differed quite significantly. Twenty-eight of 32 patients ( 87 per cent) in the methohexitone group were willing to accept the same anaesthetic again compared to only 20 of 32 patients (62 per cent) of the ketamine group. Six patients ( 19 per cent) were undecided whether or not they would have ketamine again. Four patients ( 13 per cent) flatly refused: two of them because of unpleasant vivid dreams and the other two because they "liked Sodium Pentothal better."

\section{Discussion}

A dose of ketamine $2.2 \mathrm{mg} / \mathrm{kg}$ is generally recommended for providing anaesthesia in the average patient. This dosage frequently results in a significant percentage of patients with adverse emergence reactions and a relative prolonged period of recovery from the anaesthesia. ${ }^{3-5}$ More recently various clinical investigators have tried lower doses of ketamine producing analgesia without apparently affecting consciousness and with a reported absence or considerable reduction of psychomimetic reactions. ${ }^{0-11}$

The finding that 21 of 32 patients ( 65 per cent) did not lose consciousness after the intravenous administration of ketamine in the small doses utilized in this series, confirms previous reports by Bovill and Dundee, and others ${ }^{\text {k-9 }}$ that ketamine can produce somatic analgesia without apparent clincal impairment of consciousness. It also agrees with the previous observation by $\mathrm{Chen}^{12}$ that arylcycloalkylamines, such as ketamine, differ from barbiturates in producing a cataleptoid state without hypnosis. This clinical property added to the preservation of the laryngeal reflexes could be used with advantage as an alternative anaesthetic technique in operations on outpatients in whom the potential risk of delayed emptying of a full stomach is enhanced.

The apparent contradiction between the finding that only 4 patients of 32 in the ketamine group had complete postoperative anterograde amnesia (the combined effect of premedication and anaesthesia) and a high incidence of transient intraoperative amnesia may be explained by the sensitivity of the hippocampus to anaesthetic agents, including ketamine. ${ }^{13-18}$ The hippocampus has the lowest electrical discharge threshold among neurological structures, and has been functionally linked to the neurophysiological stage of short-term memory and learning. ${ }^{19,20}$

We questioned our patients about dreams within the first 15 minutes after their arrival in the recovery room and still 6 of 32 patients claimed they had dreams after the intravenous administration of subanaesthetic doses of ketamine. Because we did not record electroencephalograms in these patients we could not confirm the existence of dream sleep patterns. We can only say that unpleasant dream-like activity appears to be unrelated to the dosage of ketamine.

It has been shown that when ketamine is administered intravenously in anaesthetic doses without premedication, the return to full orientation can be delayed up to more than four hours. ${ }^{21}$ Conversely, intravenous methohexitone is the fastest among 
the ultra-short acting barbiturates in regard to recovery to full orientation. Since there was no significant difference of recovery to orientation in the two groups, we can say that ketamine as sole agent administered in small doses compares favourably with methohexitone in regard to the recovery to orientation, when light premedication is used.

Visual disturbances can be prolonged and annoying for the patients after the administration of ketamine in anaesthetic doses. ${ }^{22-25}$ Unfortunately this side effect is not significantly ameliorated by the premedication. ${ }^{26}$ In our series the return of clear vision among the patients receiving a small dose of ketamine was similar to those who received methohexitone. There is a direct relationship between the dose of ketamine and the frequency and intensity of visual disturbances. When we studied the recovery of the visual motor coordination by the Trieger Test in both groups of patients, we found a discordance between the apparent clinical recovery to orientation and the return of this test to the preoperative baseline values (Figure 1). Despite the fact that in the methohexitone group all the patients were clinically and fully oriented with clear vision within the first 45 minutes of their arrival in the recovery room, the Trieger Test had returned to the preoperative value at that same time in only 13 of 24 patients ( 51 per cent). This discrepancy was even more evident in the ketamine group, in which the test returned to baseline value in only 8 of 32 patients ( 36 per cent) in the same period of time. This indicates that ketamine, even when administered in sub-anaesthetic doses can impair the psychomotor visual coordination of the patients for a relatively long time.

\section{SUMMARY}

Sub-dissociative doses of ketamine compared unfavourably with methohexitonenitrous oxide anaesthesia for dilatation, evacuation and curettage. We could not separate the desirable effects of analgesia and amnesia from the unwanted dream effects and visual disturbances. Although the time to clinical recovery was similar, the Trieger Motor Test revealed a delay in return to normal in both groups.

\section{RÉSUMÉ}

Pour des interventions de courte durée, par exemple des dilatations et curettages utérins, la Kétamine à dose "sous-dissociative" est une méthode moins satisfaisante qu'une anesthésie générale avec Méthohexital, protoxyde d'azote et oxygène. Les stades d'analgésie et d'amnésie ne peuvent être atteints sans incidence significative de cauchemars et de troubles visuels. La durée de l'éveil est comparable chez les deux groupes; le test de Trieger a mis en évidence un délai au retour de la coordination motrice oculaire dans les deux groupes comparés.

\section{REFERENCES}

1. Newman, M.G., Trieger, D.M.D., \& Millen, J.C. Measurement recovery from anesthesia - Simple Test. Anesth. Analg. 48: 136-140 (1969).

2. Gruber, R.P. \& Reed, D.R. Postoperative anterograde amnesia. Brit. J. Anaesth. 40: 845849 (1968). 
FIGALLO, et al.: KETAMINE AND SODIUM METHOHEXITAL-NITROUS OXIDE $\mathrm{O}_{2} \quad 117$

3. Ketamine drug description inserts. Ketamine "special note" Bristol Laboratories and ParkeDavis \& Company (1974).

4. Sussman, D.R. A comparative evaluation of ketamine anesthesia in children and adults. Anesthesiology 40:459-464 (1974).

5. LANGEHR, D. \& Neuhaus, R. Ketamine indications, controversial special aspects and disadvantages. Acta Anesth. Belg. 2: 71-96 (1973).

6. BovilL, J.G. \& DundeE, J.W. Alterations in response to somatic pain associated with anesthesia XX: ketamine. Brit. J. Anaesth. 43: 496-498 (1971).

7. Sadove, M.S., Shulman, M., Hatano, S., et al. Analgesic effects of ketamine administered in subdissociative doses. Anesth. Analg. 50:452-457 (1974).

8. Hyman, M.D. Use of small dosage of ketamine in obstetrics. Anesth. Rev. 1: 17-19 (1974).

9. Slocoff, S., Allen, G.W., Wessels, J.V., et al. Clinical experiences with subanesthetic ketamine. Anesth. Analg. 53: 354-358 (1974).

10. Chopoff, P. \& Stella, J.C. Use of Cl-581: a phencyclidine derivative for obstetric anesthesia. Anesth. Analg. 45: 527-530 (1966).

11. Conssen, G., Hayward, K., Gunter, J.W., et al. A new anesthetic for oral surgery. J. Oral Surg. 27: 627-632 (1969).

12. Chen, G. The pharmacology of ketamine: ketamine anesthesiology and resuscitation. (Editor: H. Kreuscher) 40:1-11 (1969).

13. MIYAsaka, M. \& Domino, E.F. Neuronal mechanisms of ketamine-induced anesthesia. Int. J. Neuropharmacol. 7: 559-573 (1968).

14. Winters, W.D. \& Ferrar-Allado, T. The cataleptic state induced by ketamine: a review of neuropharmacology of anesthesia. Neuropharmacology 11: 303-315 (1972).

15. Kayama, Y. \& Kayama, K. The EEG evoked potentials and single-unit activity during ketamine anesthesia in cats. Anesthesiology 30: 316-328 (1972).

16. Brazier, M.A.B. Effects of anesthesia on visually evoked responses. Int. Anaesth. Clinic. 8: 103-128 (1970).

17. Winters, W.D. Epilepsy or anesthesia with ketamine: editorial news. Anesthesiology 36 : 309-312 (1972)

18. Massopust, L.C., JR., Wolin, L.R., \& Albin, M.S. Electrophysiologic and behavioral responses to ketamine hydrochloride in the rhesus monkey. Anesth. Analg. 51: 329-341 (1972).

19. Brazier, M.A.B. Stimulation of the hippocampus in man using implanted electrodes: brain function. University of California Press 11: 299-310 (1964).

20. Routtenbers, A. The Two-Arousal Hypothesis: Reticular Formation and Limbic System. Psychological Review, 75: 51-80 (1968)

21. Kreuscher, H., \& Bonnemand, F. The influence of Ketamine (CL-581) on the postanesthetic psychophysical efficiency. Progress in Anaesthesiology. Excerpta Medical Foundation, 1203 (1970).

22. O’Neill, A.A., Minnie, A.P., Zadigan, M.E., \& Colings, V.J. Premedication for ketamine anesthesia: phase I - the "classic" drugs. Anesth. Analg. 51: 475-482 (1972).

23. Thompson, G.E., Remington, J.M., Millman, B.S., \& Bridenbaugh, L.D. Experiences with outpatient anesthesia. Anesth. Analg. 52(6): 881-887 (1973).

24. Know, J.W.D., Bovill, J.G., Clarke, R.S.J., \& DundeE, J.W. Clinical studies of induction agents. XXXVI. Ketamine. Brit. J. Anaesth. 42(10): 875-885 (1970).

25. Bovill, J.G., Coppel, D.L., Dundee, J.W., \& Moore, J. Current status of ketamine anesthesia. Lancet $1: 1285-1288$ (1971).

26. Bovill, J.G., Clarke, R.S.J., Dundee, J.W., Pandit, S.K., et al. Clinical Studies of Induction Agents: XXXVIII: Effect of premedicants and supplements on ketamine anesthesia. Brit. J. Anaesth. 43: 600-608 (1971). 